\title{
Correspondence
}

\section{The optic disc in glaucoma}

SIR, The article by Hitchings and Wheeler ${ }^{1}$ demonstrates the difficulty in recognising nerve fibre layer loss in glaucoma. Except for a single case they noted no difference in the visibility of the nerve fibre layer between normotensive eyes and hypertensive mates of 10 patients with uniocular hypertension. Yet another case, illustrated in Fig. 4 of their article, clearly shows this difference. Nerve fibre layer striations are far more apparent in the normotensive than the hypertensive eye. The loss of nerve fibre layer is confirmed by the sharper definition of major vessels in the hypertensive eye. These changes are most apparent in the area of the superior temporal vein.

Nerve fibre layer loss can be recognised by slit-like defects, ${ }^{2}$ but also by thinning of the nerve fibre layer as it crosses the temporal rim $^{3}$ and as a general loss of striations and prominence of the major vessels near the disc. ${ }^{24}$ Unfortunately these changes are often difficult to recognise. Better, more reproducible techniques for visualising the nerve fibre layer and its abnormalities are clearly needed. Wilmer Ophthalmological Institute,

ALFRED SOMMER $600 \mathrm{~N}$ Wolfe Street.

Baltimore,

Maryland 21205,

USA.

\section{References}

1 Hitchings RA, Wheeler CA. The optic disc in glaucoma. IV: Optic disc evaluation in the ocular hypertensive patient. BrJOphthalmol 1980; 64: 232-9.

2 Sommer A. Miller NR, Pollack I, Maumenee AE. George T. The nerve fiber laver in the diagnosis of glaucoma. Arch Ophthalmol $1977 ; 95 ; 2149-56$.

3 Sommer A. Pollack I. Maumenee AE. Optic disc parameters and onset of glaucomatous field loss. 1. Methods and progressive changes in disc morphology Arch Ophthalmol 1979; 79: 1444-8.

4 Quiglev HA. Miller NR. George T. Clinical evaluation of nervefiber laver atrophy as an indicátor of glaucomatous optic nerve damage. Arch Ophthalmol 1980; 98: 1564-71.

SIR, We thank Dr Sommer for his interest in our article and fully endorse his view that slit-like defects in the retinal nerve fibre layer are important evidence of neuronal loss. Caution must be used, however, when interpreting general loss of visibility of the nerve fibre layer as seen on photographs, for this appearance may be altered by refocusing the camera. The 2 photographs illustrated are of the same eye seen in Fig. 4 of our article, taken at the same visit but at different focus. A difference in visibility in the retinal nerve fibre layer is apparent on comparing the 2 . Thus while intraphotography differences in neuronal visibility may accurately reflect neuronal loss, inter-photograph differences may reflect different focusing levels; we consider that this reason accounts for the change noted by $\mathrm{Dr}$ Sommer.

A second major problem arises when interpreting the lack of visibility in the retinal nerve fibre layer as evidence
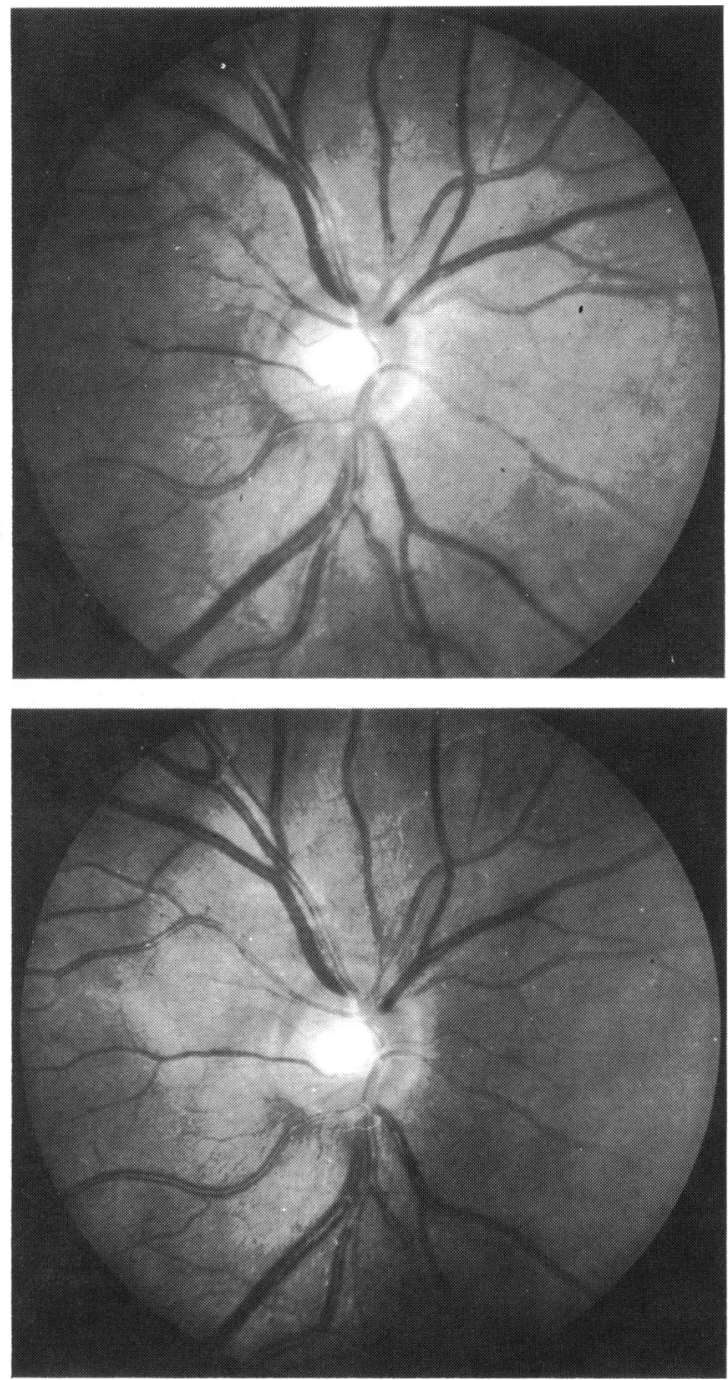

for neuronal loss in glaucoma patients, for many patients will have minor degrees of opacification of the lens. This opacification combined with an inability to dilate the pupil fully will suffice to prevent clear visualisation of the nerve fibre layer.

Moorfields Eye Hospital.

ROGER A. HITCHINGS

High Holborn.

London WCIV 7AN.

\section{The measurement of cyclofusional response}

SIR. In their recent paper Sen et al. ${ }^{1}$ claimed to have measured torsional fusional vergence by a synoptophore 
method. It has been generally accepted ${ }^{2}$ that human fusional response to retinal image disparity contains 2 components: a motor component in the form of compensatory, vergence eye movements and a sensory or nonmotor component described by the extent of Panum's fusional areas. Objective measurements of cyclofusional response, which utilised binocular eye movement monitoring devices, revealed a substantial sensory component in cyclofusional response. ${ }^{3-6}$ The magnitude of this sensory component is a function of stimulus complexity and of the visual angle subtended by the stimulus. Subjective methods such as the one used by Sen et al. may be used to measure the overall amplitude of cyclofusional response, but cannot be used to measure the amplitude of either the motor or the sensory components individually, because the method is unable to distinguish between the 2 components. Therefore Sen et al. could not have measured torsional vergence (a term reserved exclusively for the description of the motor component) as was indicated in their paper, but only the overall cyclofusional response. I think that the interesting results of Sen et al. may be better appreciated subsequent to this correction in terminology.

Biomedical Center, ANDREW E. KERTESZ

Northwestern University and

Division of Ophthalmology,

Evanston Hospital,

2145 Sheridan Road,

Evanston, IL 60201, USA.

\section{References}

1 Sen DK. Singh B. Mathur GP. Torsional fusional vergences and assessment of cyclodeviation by synoptophore method. $\mathrm{Br} \mathrm{J}$ Ophthalmol 1980; 64: 354-57.

2 Parks MM. Ocular Motility and Strabismus. New York: Harper Row, 1975: 40 .

3 Crone RA. Everhard-Halm Y. Optically induced eye torsion Albrecht von Graefes Arch Klin Opthalmol 1975; 195: 231-9.

4 Kertesz AE. Sullivan MJ. The effect of stimulus size on human cvclofusional response. Vision Res 1978; 18: 567-71.

5 Sullivan MJ. Kertesz AE. Binocular coordination of torsional eye movements in cyclofusional response. Vision Res 1978; 18: 943-49.

6 Sullivan MJ. Kertesz AE. Peripheral stimulation and human cyclofusional response. Invest Ophthalmol Visual Sci 1979; 18: 1287-91.

SIR. We were very interested to read Dr Kertesz's comments about our paper. ${ }^{1}$ We agree that the subjective method used by us measured the overall amplitude of cyclofusional response. We are aware that Parks $^{2}$ has used the term 'fusional vergence' to mean the motor component of fusion. But our impression is that the term 'torsional fusional vergence' is more often used to mean the overall amplitude of cyclofusional response rather than only the motor component. Parks ${ }^{3}$ used a subjective method and stated that the normal person had an incyclovergence of $6^{\circ}$ to $10^{\circ}$ and an excyclovergence of $8^{\circ}$ to $12^{\circ}$. Bullock and Bredemeyer ${ }^{4}$ reported incyclovergence to be $6^{\circ}$ to $10^{\circ}$ and excyclovergence to be $4^{\circ}$ to $8^{\circ}$. In view of the fact that the motor component of cyclofusion is small ${ }^{5}$ or absent ${ }^{6}$ we presumed with justification that what Parks, ${ }^{3}$ Bullock and Bredemever. ${ }^{4}$ and $\mathrm{Kramer}^{7}$ meant by 'torsional fusional vergence' was nothing but the overall cyclofusional response and not merely its motor component. Since we wanted to compare our data with those of Parks, ${ }^{3}$ Bullock and Bredemeyer, ${ }^{4}$ and Kramer $^{7}$ we retained the term 'torsional fusional vergence' to avoid confusion.

V/4 MAM College Campus,

D. K. SEN

Kotla Road,

New Delhi 110002 ,

India.

\section{References}

1 Sen DK. Singh B. Mathur GP. Torsional fusional vergences and assessment of cyclodeviation by synoptophore method. Br J Ophthalmol 1980; 64: 354-7.

2 Parks MM. Ocular Motility and Strabismus. New York: Harper Row, 1975: 40.

3 Parks MM. Ocular Motility and Strabismus. New York: Harper Row, 1975: 65.

4 Bullock K. Bredemeyer HG. Orthoptics: Theory and Practice. St Louis: Mosby. 1968: 75.

5 Ellerbrock VJ. Inducement of cyclofusional movements. Am J Optom Physiol Opt 1954; 31: 553-66.

6 Kertesz AE. Jones RW. Human cyclofusional response. Vision Res 1970; 10: 891-6.

7 Kramer ME. Clinical Orthoptics. Diagnosis and Treatment. 2nd ed. St Louis: Mosby, 1953: 480 .

\section{Oculocardiac reflex}

SIR, A recent article ${ }^{1}$ by Drs Apt and Isenberg described the usefulness of the oculocardiac reflex in identifying and recovering a lost muscle. The authors make the observation that a chronically lost muscle may be difficult to identify visually, 'often blending into the surrounding tissues.' They also correctly point out that the 'area to be explored often has adhesions and extraneous tissue.'

It is not clear to me how the surgeon can be certain that he is not pulling on nonmuscular scar tissue which has adhered to the true muscle, thereby producing a vagal response. This false muscle identification would lead to surgery (recession, resection, advancement) on nonmuscular tissue, which would not correct the patient's strabismus. Also, in a recent paper by Drs Parks and Bloom ${ }^{2}$ it was demonstrated that in certain cases the muscle capsule may remain attached to the surgical insertion site on the sclera, while the muscle itself slipped back within the capsule; surgery performed on the nonmuscular capsular tissue was ineffective in correcting these patients' motility problems. The oculocardiac reflex was not investigated in this study. However, it is reasonable to expect that, since the capsule remained intimately attached to its muscle, pulling on the capsule would stretch the muscle and produce the oculocardiac reflex.

Drs Apt and Isenberg have made an important observation in the treatment of both the lost and the slipped muscles. However, the surgeon must be aware that production of the oculocardiac reflex may represent a false-positive result in the identification of a lost or slipped muscle.

Marshall Taylor Building. JEFFREY N. BLOOM 836 Prudential Drive, Suite 555.

Jacksonville.

Florida 32207.

USA. 